\title{
Bladder-neck Opening Test in Spinal Cord Injury Patients using a New i.v. Alpha-blocking Agent, Alfuzosin
}

\author{
P. Cramer, MD,${ }^{1}$ E. Neveux, $M D,{ }^{1}$ F. Régnier, MD,${ }^{1}$ J. Depassio, $M D,{ }^{2}$ \\ E. Bérard, $\mathbf{M D}^{2}$ \\ ${ }^{1}$ Laboratoires d'Etudes et de Recherches Synthélabo (LERS), Départment de Re- \\ cherche Clinique, 58 Rue de la Glacière, 75013 Paris, France, ${ }^{2}$ Service de Rééduca- \\ tion et Réadaptation Fonctionnelles Hôpital Renée Sabran, Bd Edouard Herriot, \\ Giens 83406 Hyères Cédex, France.
}

\begin{abstract}
Summary
A bladder-neck opening test using alfuzosin, a new alpha-adrenoceptor blocking agent, was carried out in 21 patients with spinal cord injury. The efficacy of alfuzosin was assessed with 4 simple urodynamic parameters: micturition, residual urine, posterior urethral pressure and diameter. Both mean urethral pressure and diameter were significantly affected after the administration of $5 \mathrm{mg} i . v$. alfuzosin. The test was clinically positive in 18 patients: 11 out of 13 patients using intermittent catheterisation or continuous drainage urinated and 6 out of 8 patients already tapping had reduced residual urine volumes. A decrease in posterior urethral pressure was also observed in 2 out of 3 patients who did not respond clinically to alfuzosin. Alfuzosin was well tolerated during this test. Oral alfuzosin should therefore be investigated in patients who gave a satisfactory response to such a test.
\end{abstract}

Key words: Spinal cord injury; Urodynamics; Alpha-blocking agent; Alfuzosin.

During spinal shock following spinal cord injury, urethral profile activity is stable but remains static throughout bladder filling (Awad et al., 1977), regardless of the site of injury (McGuire et al., 1977; Rossier and Ott, 1976). Later, when a reflex activity has appeared below the site of the lesion, even though the pattern of dysfunction varies with the site and extent of the lesion, the incidence of inappropriate urethral resistance is high, irrespective of the site of the injury (Buzelin and Labat, 1984; McGuire et al., 1977; Scott and Morrow, 1978).

Bladder neck and urethral smooth-muscle sphincter have been reported to be mainly supplied by adrenergic nerves and are essentially provided with alpha-1adrenergic receptors (Gosling et al., 1977; McGuire, 1986). Earlier studies have shown the beneficial effect of alpha-blockers in patients with neurogenic bladder voiding dysfunction (Awad et al., 1977; Buzelin et al., 1984; Tulloch and Rossier, 1977). Alfuzosin is a new alpha-blocker with a high degree of selectivity for alpha-1-adrenoceptors (Cavero et al., 1984, 1985). The drug is available in i.v. and oral formulations. 
This study was designed to evaluate the effect of one does of i.v. alfuzosin on micturition in patients with spinal cord injury in order to predict the potential efficacy of the oral formulation. The results of this test might also help in the understanding of the mechanism of the vesico-sphincteral dysfunction.

\section{Patients and methods}

The study was performed in 21 patients, 6 women and 15 men (mean age $31.6 \pm 3.8$ years, range 17-68 years). Two patients had incomplete tetraplegia. Nineteen patients were paraplegic; lesions were complete in 13 patients and incomplete in the remaining 6 . All but 3 had experienced spinal cord injury for more than 3 months.

Evaluation of the vesical and urethral dysfunction was made according to clinical neurological assessments, intravesical and posterior urethral pressure recordings, cystography and urethral sphincter electromyography; the latter parameter was evaluated independently from pressure recordings. In all but 3 patients, the pattern of lower urinary tract dysfunction was reflex. The external urethral sphincter was hypertonic in 5 patients, but dyssynergic in only 1 of them. The detrusor was hypotonic or flaccid in 11 patients. In 10 patients intermittent catheterisation was used to empty their bladder and 3 patients had continuous catheter drainage. Eight patients were already tapping.

The pharmacological test itself was carried out as follows: 10 patients with hypotonic or flaccid detrusor received subcutaneous bethanechol chloride $(0.5 \mathrm{mg} / 10 \mathrm{~kg})$, a parasympathomimetic agent, prior to the administration of alfuzosin in order to reinforce bladder voiding pressure (Buzelin et al., 1984); $5 \mathrm{mg}$ of alfuzosin was administered intravenously, over 20 minutes, using an electric infusion pump. Chart recordings of bladder and intra-urethral pressures were obtained using a Buselin two-way catheter and an electronic microtransducer connected to a two-way Hewlett Packard recorder (infusion rate $15 \mathrm{ml} /$ min, paper speed: $20 \mathrm{~mm} / \mathrm{min}$ ). Posterior urethral pressure was measured halfway between the bladder neck and the external sphincter; the localisation of the catheter was checked using X-rays. In all cases, the largest pressure drop was considered. Instantaneous micturitional X-rays enabled the vesico-urethral junction to be visualised and the urethral diameter to be measured. An X-ray index was used to measure urethral diameter (Figure) and urethral pressure was measured under the same conditions before and after administration of alfuzosin. Bladder filling was stopped just before the infusion of the drug, in order to maintain a steady volume. Intravesical pressure was checked simultaneously using the two-way catheter and monitored with the bladder X-ray picture. Bladder neck opening was visualised on instantaneous X-ray pictures, before and after administration of alfuzosin, at the maximum of bladder pressure rise following suprapubic tapping. In all cases, measurements were repeated twice.

The test was considered to be fully positive if suprapubic tapping was followed by micturition in less than 5 minutes in the patients using intermittent catheterisation or continuous drainage. In the patients already tapping, positivity was linked to a clear decrease in residual urine (less than $30 \%$ of the voided volume after the test). Heart rate and blood pressure were monitored during the test. Fully written informed consent was obtained from each patient. 


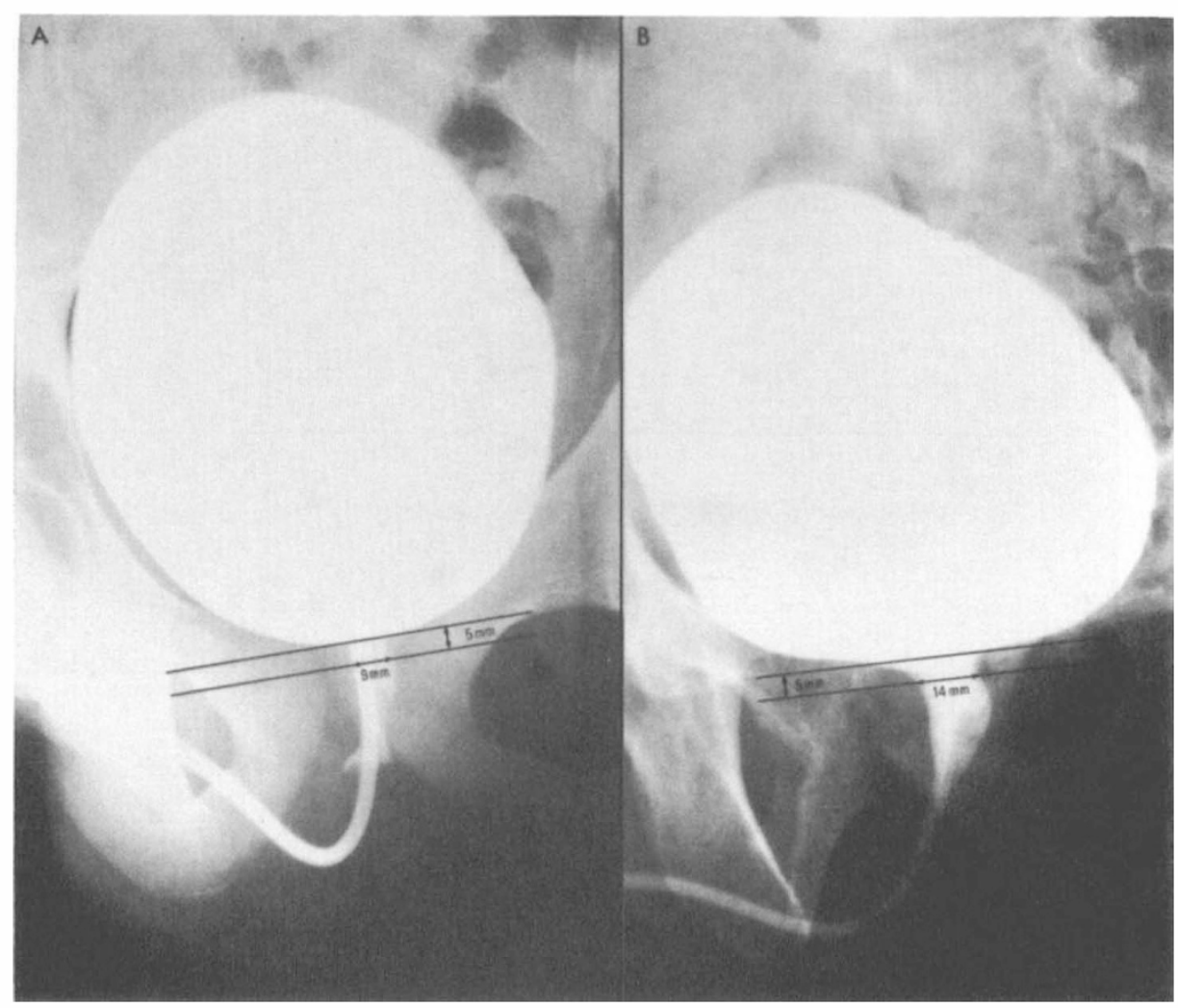

Figure Instantaneous $\mathrm{X}$-ray picture showing the index used to measure posterior urethral diameter. A: Before alfuzosin, B: After alfuzosin.

Comparison of data before and after the administration of alfuzosin was made using a t-test for matched pairs. The reported $\mathrm{p}$ levels are for two-tailed tests.

\section{Results}

Complete or incomplete micturition occurred in 12 out of the 13 patients who did not urinate before. Among the 8 patients already tapping, 5 patients had clearly reduced residual volumes and 1 patient with no residual urine before the test had a much easier micturition. Altogether, 18 out of 21 patients responded clinically to alfuzosin.

Mean changes in urodynamic parameters are reported in Table I: both posterior urethral pressure and bladder-neck opening (urethral diameter) were significantly affected after the administration of alfuzosin. The mean posterior urethral pressure fell from 27.7 to $12.4 \mathrm{~cm} \mathrm{H}_{2} \mathrm{O}$ and the mean urethral diameter increased from 3.9 to $10.6 \mathrm{~mm}$. Detrusor pressure was not significantly reduced after alfuzosin (data not shown) as previously reported by others with prazosin (Jensen, 1981a).

Three patients failed to respond clinically to alfuzosin. Their individual urodynamic data are given in Table II: patients 12 and 21 had a significant drop in urethral pressure; patient 21 also had a clear increase in urethral diameter. Patient 16 did not have significant changes in any of the 2 urodynamic parameters. 
Table I Effects of $5 \mathrm{mg}$ i.v. of alfuzosin on urodynamic parameters

\begin{tabular}{lcc}
\hline & $\begin{array}{c}\text { Urethral pressure } \\
\left(\mathrm{cm} \mathrm{H}_{2} \mathrm{O}\right)\end{array}$ & $\begin{array}{c}\text { Urethral diameter } \\
(\mathrm{mm})\end{array}$ \\
\hline $\begin{array}{l}\text { Number of patients } \\
\text { Pre-treatment assessment }\end{array}$ & $19^{\star}$ & $20 \star \star$ \\
$\quad$ mean \pm sem & $30.5 \pm 3.4$ & $3.9 \pm 1.0$ \\
$\quad$ range & $10-54$ & $0-11$ \\
After alfuzosin & & $10.6 \pm 1.0$ \\
$\quad$ mean \pm sem & $12.8 \pm 1.9$ & $0-18$ \\
range & $0-34$ & $+6.7 \pm 1.1$ \\
Variation & $-58^{\circ}{ }_{0}$ & 0.0001 \\
p value & 0.0001 &
\end{tabular}

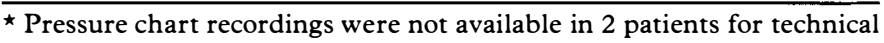
reasons.

$\star \star$ Urethral diameters were not available in 1 patient.

Table II Changes in urodynamic data in the 3 patients who failed to respond clinically to alfuzosin

\begin{tabular}{|c|c|c|c|c|c|c|}
\hline \multirow[b]{2}{*}{$\begin{array}{c}\text { Case } \\
\text { no. }\end{array}$} & \multirow[b]{2}{*}{ Type of lesion } & \multirow[b]{2}{*}{ Voiding mode } & \multicolumn{2}{|c|}{$\begin{array}{l}\text { Urethral pressure } \\
\qquad\left(\mathrm{cm} \mathrm{H} \mathrm{H}_{2} \mathrm{O}\right)\end{array}$} & \multicolumn{2}{|c|}{$\begin{array}{l}\text { Urethral diameter } \\
\qquad(\mathrm{mm})\end{array}$} \\
\hline & & & $\begin{array}{l}\text { Pre-treatment } \\
\text { assessment }\end{array}$ & $\begin{array}{l}\text { After } \\
\text { alfuzosin }\end{array}$ & $\begin{array}{l}\text { Pre-treatment } \\
\text { assessment }\end{array}$ & $\begin{array}{c}\text { After } \\
\text { alfuzosin }\end{array}$ \\
\hline 12 & $\begin{array}{l}\text { Incomplete reflex } \\
\text { paraplegia with } \\
\text { hypotonic bladder }\end{array}$ & $\begin{array}{l}\text { Intermitent } \\
\text { catheterisation }\end{array}$ & 44 & 18 & 0 & 0 \\
\hline 16 & $\begin{array}{l}\text { Incomplete reflex } \\
\text { paraplegia with } \\
\text { hypotonic bladder }\end{array}$ & Tapping & 28 & 20 & 7.5 & 8 \\
\hline 21 & $\begin{array}{l}\text { Conus medullaris } \\
\text { syndrome with } \\
\text { normotonic bladder }\end{array}$ & Tapping & 70 & 12 & 0 & 12.5 \\
\hline
\end{tabular}

Alfuzosin was well tolerated during the test. One patient complained of feeling cold. Only 2 episodes of moderate tachycardia and 1 case of hypotension (105/50 $\mathrm{mmHg}$ versus $125 / 75 \mathrm{mmHg}$ prior alfuzosin) were reported during the test. The effect of alfuzosin on heart rate and blood pressure is shown in Table III.

\section{Discussion}

This test, reliable because of its simplicity and reproducibility, assessed the effect of $5 \mathrm{mg}$ i.v. of alfuzosin, a new alpha-blocking agent, on 4 simple urodynamic parameters (micturition, residual urine, posterior urethral pressure and diameter). This was performed in 21 patients with neurogenic lower urinary tract dysfunction. The overall results of the test were positive in 20 patients since a partial response with a decrease in posterior urethral pressure was also observed in 2 out of 3 patients who did not respond clinically to the administration of alfuzosin. However the quality of the response varied between patients. This can be explained, not only by the extent of outflow resistance and intensity of the alpha-blocking effect, but also by the detrusor contractility. The detrusor 
Table III Effects of $5 \mathrm{mg}$ i.v. alfuzosin on haemodynamic parameters

\begin{tabular}{|c|c|c|c|}
\hline & \multirow{2}{*}{$\begin{array}{l}\text { Heart rate } \\
\text { (beats/min) }\end{array}$} & \multicolumn{2}{|c|}{ Blood pressure $(\mathrm{mmHg})$} \\
\hline & & Systolic & Diastolic \\
\hline $\begin{array}{l}\text { Number of patients } \\
\text { Mean } \pm \text { sem }\end{array}$ & 21 & 21 & 21 \\
\hline Before alfuzosin & $83 \pm 3 \cdot 4$ & $114.0 \pm 6.0$ & $63.8 \pm 4.0$ \\
\hline After alfuzosin & $91.3 \pm 3.8$ & $108.3 \pm 5.7$ & $60.5 \pm 2.8$ \\
\hline $\begin{array}{l}\text { Variation } \\
\mathrm{p} \text { value }\end{array}$ & $\begin{array}{l}+10^{\circ}{ }^{\circ} \\
0.002\end{array}$ & $\begin{array}{l}-5^{\circ}{ }^{\circ} \\
0.01\end{array}$ & N.S. \\
\hline
\end{tabular}

function itself varies with the site of the lesion and the time elapsed since the injury (McGuire et al., 1977). Therefore, this test should not be performed until at least 6 months after the injury, when detrusor activity has stabilised.

The overall positive results of this test confirmed the increased sympathetic tone of the posterior urethra in the majority of patients with spinal cord injury (McGuire et al., 1977) and the alpha-blocking activity of alfuzosin on posterior urethral pressure and diameter, and similarly, the predominant adrenergic supply of this part of the lower urinary tract. With the patients having a poor response to alfuzosin because of an inadequate bladder contractility, X-rays showed a widening of the junction only at the level of the posterior urethral portion and not above, thus suggesting a lack of involvement of the bladder fibres of the junction in the pharmacological response (Figure). These results are in agreement with the findings of Gosling who reported a sparse distribution of adrenergic nerves in the bladder neck (Gosling et al., 1977) but somewhat opposed to the finding of others (Ek et al., 1977; Sundin et al., 1977).

In the patients with a good response to the test, i.e. micturition with an efficient voiding and little residual urine, oral alfuzosin could be proposed as a mid- or long term medication, whereas it might not be recommended to patients with a weak or negative response to the test. Patients with a poor bladder contractility should use intermittent catheterisation and those with an efficient voiding pressure, therefore at risk of renal destruction, should have urethroscopy and probably sphincterotomy (McGuire, 1986).

Although pharmacological blockade of the sympathetically innervated bladder neck has already been achieved with other alpha-blocking agents (Jensen, 1981a; Scott and Morrow, 1978) alfuzosin seems of particular interest. Indeed, the availability of two formulations may make it possible to carry out such an i.v. test and to continue with the oral medication in the patients who have given a satisfactory response to this test. Further studies will be required to determine if the oral formulation can produce similar effects and which is the appropriate dosage. In this study, alfuzosin has also shown significant efficacy together with very few and minor adverse reactions.

\section{Acknowledgements}

We thank the team of the Département de Radiologie de l'Hôpital Renée Sabran, for their most valuable work and $M$. Rouillard for editing the paper. 


\section{References}

AWAD SA, BRYNIAK SR, DowNIE JW, et al. 1977 Urethral pressure profile during the spinal shock stage in man: a preliminary report. Fournal of Urology 117:91-93.

BUZELIN JM, LABAT J-J 1984 Physiopathologie et classification des vessies neurologiques. In: Buzelin JM (ed) Neuro-urologie. Expansion Scientifique Française, Paris, page 18.

Buzelin JM, De Leval J, Cozian A 1984 Traitement des dysfonctionnements vésico-sphinctériens neurologiques. In: Buzelin JM (ed) Neuro-urologie. Expansion Scientifique Française, Paris, page 71.

CAvero I, LefEvre-Borg F, MANOURy P 1984 Alfuzosin, an antihypertensive agent with alpha-1adrenoceptor antagonist properties. Federation Proceedings 43(3):2627.

CAvero I, Hicks PE, Lefevre-Borg F 1985 Alpha-1-adrenoceptor antagonist effects of alfuzosin in rabbit and dog lower urinary tract. British fournal of Pharmacology 86 (Abstract $416 \mathrm{P}$ ).

Ek A, Alm P, ANDersson KE, Persson CG 1977 Adrenoceptor and cholinoceptor mediated responses of the isolated human urethra. Scandinavian fournal of Urology and Nephrology 11:97-102.

GosLing JA, Dixon JS, LENDON RG 1977 The autonomic innervation of the human male and female bladder neck and proximal urethra. Fournal of Urology 118:302-305.

JENSEN D 1981a Uninhibited neurogenic bladder treated with prazosin. Scandinavian fournal of Urology and Nephrology 15:229-233.

JENSEN D $1981 \mathrm{~b}$ Pharmacological studies of the uninhibited neurogenic bladder III. The influence of adrenergic excitatory and inhibitory drugs on the cystometrogram of neurological patients with normal and uninhibited neurogenic bladder. Acta Neurologica Scandinavia 64:401-426.

MCGUIRE EJ 1986 The innervation and function of the lower urinary tract. Fournal of Neurosurgery 65:278-285.

MCGUIRE EJ, WAGNER F, WEISS RM 1977 Urethral closing pressure after spinal-cord injury and its relationship to automatic dysreflexia. Urologia Internationalis 32: 97-106.

ROSSIER AB, OTT R 1976 Bladder and urethral recordings in acute and chronic spinal cord injury patients. Urologica Internationalis 31: 49-59.

ScOTt MB, MORROW JW 1978 Phenoxybenzamine in neurogenic bladder dysfunction after spinal- cord injury. I. Voiding dysfunction. Fournal of Urology 119:480-483.

TULlOCH AGS Rossier AB 1977 The action of neuropharmacologic agents on the bladder and urethra during experimental spinal shock. Investigative Urology 14:312-316.

SUNDIN T, DAHLSTROM A, Norlen L, et al. 1977 The sympathetic innervation and adrenoreceptor function of the human lower urinary tract in the normal state and after parasympathetic denervation. Investigative Urology 14: 322-328. 